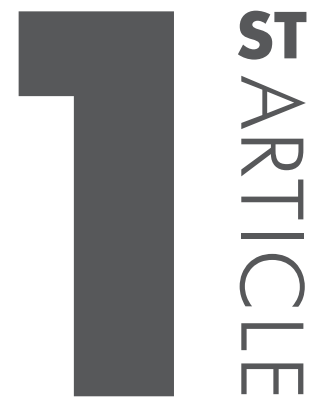

\title{
Strategies to Promote the Innovation in Brazilian Industry: The creation of SENAI Institute of Innovation
}

The measures to support innovation announced in March 2013 by President Dilma Rousseff represent a major advance for Brazil, to the extent that consensus is that Brazil needs to innovate, develop new technologies and add value to products and processes and services, so that domestic industry can be more competitive, both nationally and globally. At the same time, with the announcement of the Innovates Company Plan (Plano Inova Empresa), the Confederation of National Industries - CNI - signed a technical cooperation agreement with the BNDES - National Bank for Economic and Social Development, in order to promote business innovation through Centers of Innovation related with Federations of Industries and SENAI Institutes of Technology and Innovation. The proposal was to identify possible specific demands of business innovation that can receive support from BNDES. This action was an indication that, for the CNI, innovation is crucial for the Brazilian industry to add value to the various stages of production, create more and better jobs, increase productivity and become more competitive. To meet the challenge of innovation, CNI established in 2008 the so-called MEI (Mobilização Empresarial para a Inovação), a Business Innovation Movement, which involves the private sector and the Federal Government. The 
initiative aimed to put innovation at the center of corporate strategy of companies, as a way to strengthen the dialogue with the government and participate in the development of public policies to support technological development in the industry. As a way to consolidate a culture of innovation in industry and raise awareness that most companies should adopt innovation as a constant practice, a National Network of Centers of Innovation State was then created. By 2013 there were 23 State Centers of Innovation network participants. In addition, a partnership with the Brazilian Service of Support for Micro and Small Enterprises-Sebrae provided consulting services for the preparation and implementation of innovation plans for micro and small enterprises. The result of this agreement shows the great effort to implement a culture of innovation in businesses, where 615 companies participated in this training process. In order to strengthen further this movement, the Ministry of Science, Technology and Innovation (MCTI) in partnership with the National Confederation of Industry and with the support of the Financier of Studies and Projects (FINEP) created the pilot action named Embrapii - Brazilian Enterprise for Industrial Research and Innovation. By the end of 2013 EMBRAPII had three technology research institutions as part of this pilot, namely: SENAI-Ba/CIMATEC (Unit - Manufacturing Automation); IPT (Unit - Bionanomanufatura and Materials) and INT (Unit - Energy and Health). The objective of Embrapii is therefore to promote cooperation projects between domestic enterprises and research and development institutes to generate innovative products and processes. Another contribution of the Federation of Industries System for accelerating innovation in Brazil is the creation of SENAI Institutes of Innovation - ISI "Instituto Senai de Inovação", 25 up to 2015 and 61 SENAI Institutes of Technology - IST, with investments of approximately US\$ 1.5 billion. During the first phase of this initiative, nine ISIs were created. The first of these ISIs to be inaugurated, in 2013, was SENAI Institute of Innovation in Electrochemistry, in the State of Paraná. Activities of applied research for industrial projects started in September 2013. To ensure quality in the implementation of ISI, SENAI has developed agreements to receive input from experts Massachusetts Institute of Technology - MIT (USA), and the Fraunhofer Society from Germany, with the main purpose of assisting in the preparation of $\mathrm{R} \$ \mathrm{D}$ action plans. Monthly workshops have been conducted with the Fraunhofer team since 2012 to refine the performance of the shares of ISI at the National Industry. In the case of the ISI Electrochemistry, investment is approximately of US\$20 million in equipment and construction of a new building of 10 thousand square meters. The ISI Electrochemistry was created to act on issues related to Applied Electrochemistry Industry, i.e. aligned to the needs of the productive sector, and also in anticipation of technological trends. The innovation network will operate in an integrated way with ISI and IST and obviously acting as intermediary between the academic community (Universities and research institutes) and the industry. This 
action comes against the vision of the Federal Government to bring industries to the Centers for Applied Research of Universities and Research Institutes. The inauguration of SENAI Institute for Innovation in Electrochemistry along with the First International Seminar on Industrial Innovation in Electrochemistry can be considered as a fundamental milestone in applied research for industry in Brazil.

Marcos Antonio Coelho Berton

Researcher Chief of SENAI Institute of Innovation in Electrochemistry

Luiz Carlos Ferracin

Director of ISI Electrochemistry

Filipe Miguel Cassapo

Executive Manager of International Center for Innovation 
12 